\title{
Outpatient hysteroscopy: the Calderdale and Huddersfield experience
}

This article was published in the following Dove Press journal:

Clinical Audit

24 November 2010

Number of times this article has been viewed

\author{
Emmanuel Emovon \\ Archana Ranganathan \\ Sreelatha Tumula \\ Calderdale and Huddersfield NHS \\ Trust, Halifax HX3 OPW, UK
}

Correspondence: Emmanuel Emovon Calderdale and Huddersfield NHS Trust, Halifax HX3 OPW, UK

Tel +447903 7I8044

Email eemovon@gmail.com
Aim: To audit the outpatient hysteroscopy service at Calderdale and Huddersfield National Health Service Trust in order to improve our services.

Methodology: A retrospective audit of all patients referred for outpatient hysteroscopy from April 1, 2008, to June 30, 2008. Patients were identified using a patient administration system and endoscopy register. Analysis of the total number of patients referred, their indications, number of patients eventually referred for a general anesthesia procedure, patient-waiting times from referral, and therapeutic procedures carried out.

Results: A total of 234 patients were referred for outpatient hysteroscopy during the period of our study. Most of the patients were aged 40-49 years (63\%), and majority of the referrals were for either postmenopausal bleeding (PMB) or intermenstrual/irregular bleeding. There were 97 referrals for PMB: 62 had successful outpatient hysteroscopy; 22 had ultrasound preprocedure, which showed thin endometrium, and therefore hysteroscopy was not carried out; and 13 patients deferred the procedure because of discomfort. In the intermenstrual/irregular bleeding group, hysteroscopy was successful in 94 of 105 patients. Approximately $91.2 \%$ of the patients were seen within 8 weeks from referral, and a total of 45 patients were referred for further procedure under general anesthesia.

Conclusion: Calderdale and Huddersfield National Health Service Trust has an effective diagnostic outpatient hysteroscopy service; however, there is a need to expand the service to reduce waiting times and incorporate therapeutic procedures into the service such as Versapoint polypectomy and endometrial ablation, which would in turn decrease the number of patients referred for hysteroscopy under general anesthesia.

Keywords: outpatient hysteroscopy, abnormal uterine bleeding, gynecology clinic

\section{Introduction}

Hysteroscopy is the direct endoscopic visualization of the endometrial cavity. It can be either operative or diagnostic and is usually utilized to investigate and manage symptoms of uterine bleeding and pain. ${ }^{1}$

The procedure can be carried out under general anesthesia or in the outpatient setting. In an analysis of 17,000 outpatient diagnostic hysteroscopies, only two patients had serious, potentially life-threatening complications: one angina attack and the other had hypocalcemic crisis. ${ }^{2}$

Kremer et $\mathrm{al}^{3}$ showed patient satisfaction with outpatient hysteroscopy.

Considering the above, we believed that a retrospective audit of our practice was essential in order to improve the outpatient service we offered. 
The other potential benefits we considered were for the hospital trust to achieve its 18 -week target. The aim of the 18 -week initiative is that the management cycle of all patients is completed within 18 weeks in order to decrease the patient-waiting list and the pressure on the limited number of hospital beds.

The referral source is usually either the gynecology outpatient or the direct access pathway. The direct access pathway was put in place in order to ensure that patients at an increased risk of malignancy are seen within 2 weeks from referral. It also allows triaging patients who are likely to benefit from a "see and treat" clinic. The latter group did not require urgent review.

The criteria for referral are shown in Table 1. The general rule is that all patients either seen at the hospital or at their general practitioner (GP) service, who were at high risk of malignancy, eg, postmenopausal bleeding (PMB) patients, are needed to be seen for hysteroscopy within 2 weeks.

From the patients' perspective, we believed that an efficient outpatient service meant potentially single visit, no hospital stay, and less disruption to their life as a whole.

Finally, from the clinician's perspective, we believed that there is satisfaction in being conversant with advancing technology and decreasing the ever-increasing workload.

\section{Methodology}

We carried out a retrospective study of all patients referred for outpatient hysteroscopy from April 1, 2008, to June 30, 2008.

The patients were identified using the patient administration system and endoscopy register.

We analyzed the total number of patients, the indication, the number of patients eventually referred for a general anesthesia procedure, the patient waiting times from referral, and the therapeutic procedures carried out.

Hysteroscopies were carried out using a 3.1-mm size Olympus hysteroscopy and saline as the distension medium. The patients received paracetamol or diclofenac as analgesia after procedure, if required.

Table I The criteria used for referral to outpatient hysteroscopy Criteria for direct access referral to outpatient hysteroscopy

\section{PMB}

Persistent intermenstrual/irregular bleeding in patients more than 40 years USS findings suggestive of treatable pathology eg, small polyp Incidental finding of raised endometrial thickness

Abbreviations: PMB, postmenopausal bleeding; USS, ultrasound scan.

\section{Results}

\section{Age distribution}

A total number of 234 patients had hysteroscopies during the period with majority of the patients' age ranging from 40 to 59 years (63\%; see Figure 1).

\section{Source of referral and indication}

Majority of the referrals to the hysteroscopy service were from the GPs (64\%; see Figure 2). The main indication overall for referral by GP and outpatient clinic was PMB (see Table 2).

Majority of our referrals had either PMB or intermenstrual/ irregular bleeding $86.3 \%$. The other indication for referral was cervical concerns such as cervical polyps (see Table 2).

Menopausal patients who had an incidental finding of raised endometrial thickness were referred. Patients who had intrauterine devices in-situ but thread not visible and device irretrievable were referred. Patients with small polyps with a thin base seen on ultrasound were also referred.

Four patients who had fibroids were wrongly referred to the service.

\section{Outcomes}

There were 97 patients who were referred for outpatient hysteroscopy for PMB; 62 had successful procedures, hysteroscopy was abandoned in 13 , and not required in 22 patients (Table 3 ).

The 22 patients who did not require the procedure had thin endometrium and therefore discharged. Patients who are referred for PMB are required to be seen for hysteroscopy within 2 weeks, but it may not be feasible to arrange an ultrasound prior to presentation. In addition, not all our hysteroscopists have the skills to perform a transvaginal ultrasound to check endometrial thickness before hysteroscopy.

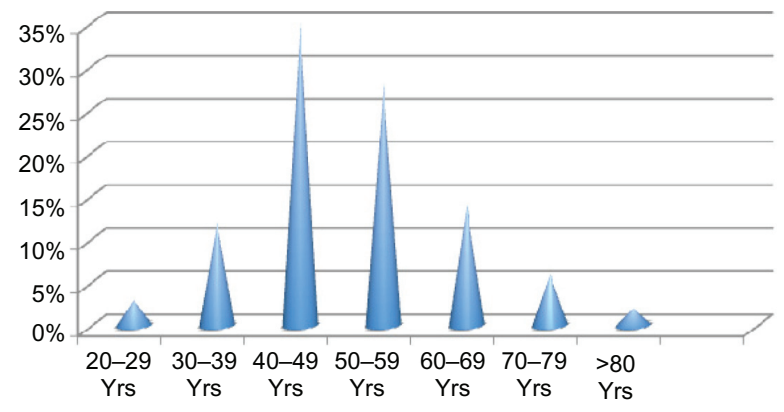

Figure I The age range of the patients referred. The majority were aged between 40 and 59 years. 


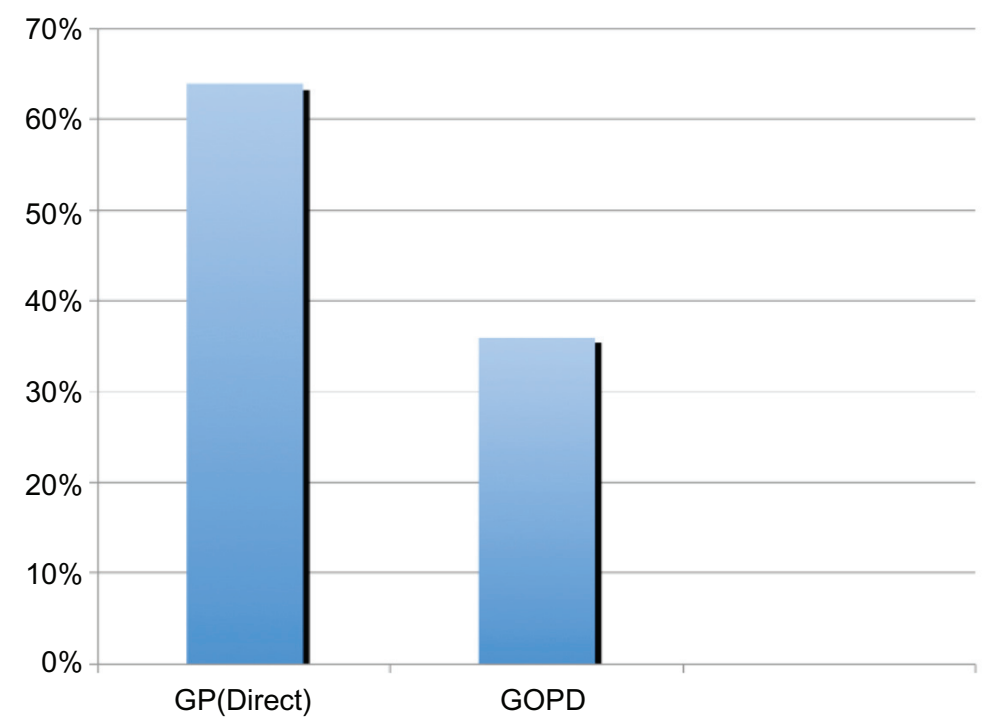

Figure 2 Most of the patients were direct referrals from general practitioners.

Abbreviations: GP, general practitioner; GOPD, general outpatient department.

Hysteroscopy was abandoned in eight patients because they were unable to tolerate the discomfort of the procedure; there were two patients with stenosed cervix and three with large polyps obstructing entry through the cervix.

These patients were subsequently referred for hysteroscopy under general anesthesia (Table 3).

Sixty-two patients had successful outpatient hysteroscopy for PMB. Thirty of the patients had atrophic endometrium as expected for their age; no biopsy was obtained in 21 of them due to their thin endometrium, whereas in the other 9 who had successful biopsies, and histology revealed a benign endometrium.

Twenty patients in the successful group had endometrial polyps. Of this group, seven were referred to have polypectomy under general anesthesia because of the large size of the polyp and its broad base. In the remaining 13 patients,

Table 2 Indication for referral $(n=234)$. Majority of the patients presented with either PMB or intermenstrual/irregular bleeding

\begin{tabular}{lll}
\hline Indication & Number & Percentage \\
\hline PMB & 97 & $41.4 \%$ \\
Intermenstrual/irregular bleeding & 105 & $44.9 \%$ \\
Cervical concerns & 8 & $3.4 \%$ \\
Raised endometrial thickness & 7 & $3.0 \%$ \\
IUCD removal & 7 & $3.0 \%$ \\
Polyp on USS & 6 & $2.6 \%$ \\
Fibroids on USS & 4 & $1.7 \%$ \\
\hline
\end{tabular}

Abbreviations: PMB, postmenopausal bleeding; IUCD, intrauterine contraceptive device; USS, ultrasound scan. histology demonstrated eight benign polyps, two with complex hyperplasia and three with neoplasia (Table 3).

\section{Outcome irregular and intermenstrual bleeding patients $(n=105)$}

Hysteroscopy was successfully carried out in 94 patients who presented with either irregular bleeding or intermenstrual bleeding (see Figure 3).

Regarding the 11 patients whose hysteroscopy was abandoned, one patient had a stenosed cervix, whereas 10 were too uncomfortable to continue the procedure.

Of the 94 patients who had successful outpatient hysteroscopy, 54 had normal-looking endometrium; histology results from these patients showed that 53 had benign endometrium and one had complex hyperplasia.

Table 3 Outcome of the PMB group

\begin{tabular}{ll}
\hline PMB group & No of referrals \\
\hline Successful & $\mathbf{6 2}$ \\
Normal-looking endometrium & 30 \\
Endometrial polyp & 20 \\
Thickened endometrium & 5 \\
Fibroids & 4 \\
Bicornuate uterus & 2 \\
Bulky uterus & 1 \\
Unsuccessful & 13 \\
Discomfort. & 8 \\
Large polyp & 3 \\
Cervical stenosis & 2 \\
Not required & $\mathbf{2 2}$ \\
\hline
\end{tabular}

Abbreviation: PMB, postmenopausal bleeding. 


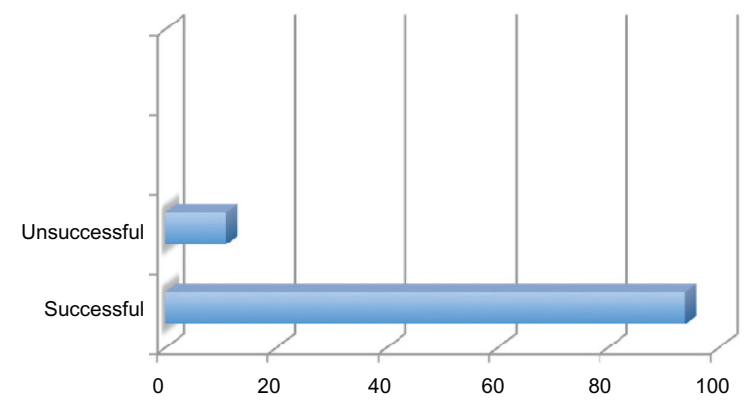

Figure 3 Outpatient hysteroscopy was successful in 94 of the 105 referred for intermenstrual/irregular bleeding.

Seventeen patients of the 94 had endometrial polyps; three of these patients were referred for polypectomy under general anesthesia because of the size of the polyps. In the remaining 14 patients, histology showed that 13 had benign endometrium, whereas 1 had neoplasia. Ten patients of the 94 had endometrium that appeared to be thickened, but histology showed benign endometrium. Eleven of the 94 patients had fibroids on hysteroscopy, and histology showed benign endometrium. Two of the 94 patients had bicornuate uterus, and their histology showed benign endometrium (Figure 4).

\section{Waiting times}

Majority of the patients were seen within 8 weeks from refer$\operatorname{ral}(208 / 228,91.2 \%$; Figure 5). (We were unable to ascertain the exact date of referral in six notes.)

Figure 6 shows the breakdown of waiting times in PMB patients. Overall, $85 \%$ of PMB patients were seen within 4 weeks. One of the patients in the 8-12 weeks group cancelled her appointment and had to be rescheduled, the remaining had benign endometrium on histology.

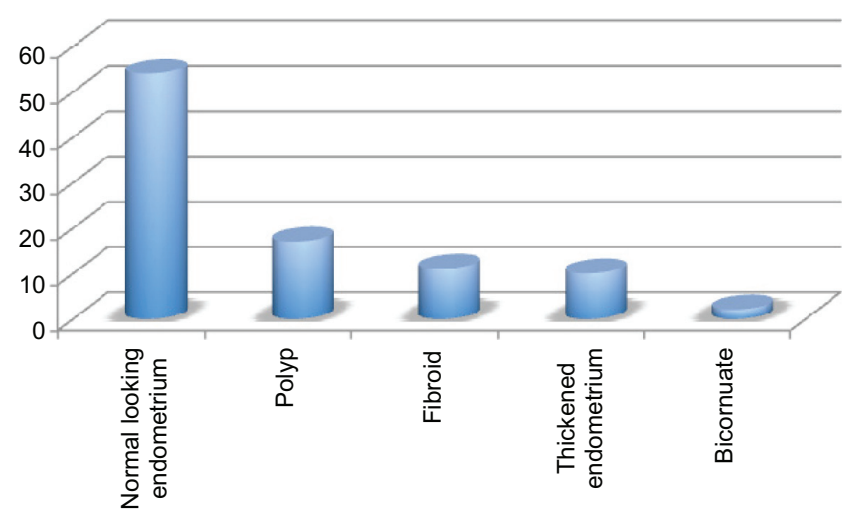

Figure 4 Outcome of successful hysteroscopies in intermenstrual/irregular bleeding group.

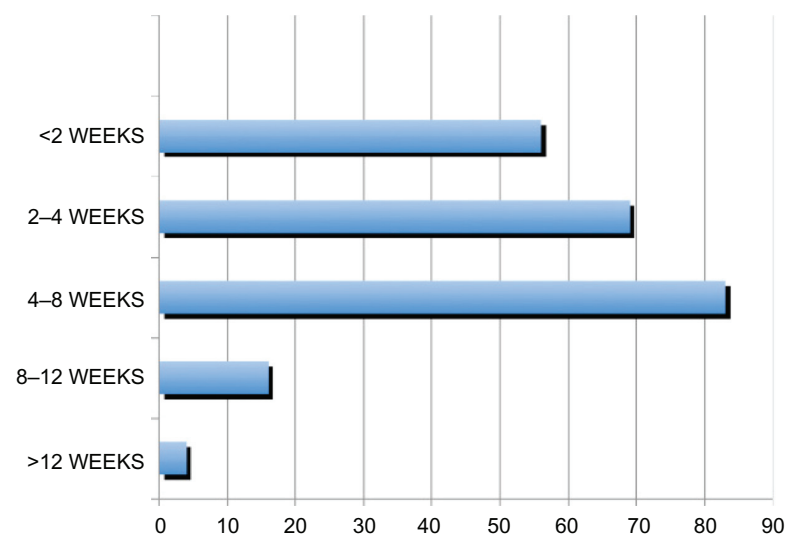

Figure 5 Most of the patients (91.2\%) were seen within 8 weeks from referral.

Figure 7 shows the distribution of patients referred for further procedure under general anesthesia. Twenty-one of the patients had unsuccessful procedure; of which 18 patients deferred procedures due to discomfort, and $3 \mathrm{had}$ stenosed cervix.

Another 21 patients had polyps of fibroids that were better resected under general anesthesia. One patient required ablation, another required large loop excision transformation zone, and one patient required intrauterine contraceptive device (IUCD) removal under general anesthesia.

\section{Discussions}

This is a pilot project with the intention to develop standards for our subsequent outpatient hysteroscopy audits.

The most common indication for referral was PMB with hysteroscopy not carried out in $22.7 \%$ (22/97) of the patients because they had endometrial thickness of less than $4 \mathrm{~mm}$ on ultrasound preprocedure.

\section{Waiting times for PMB patients}

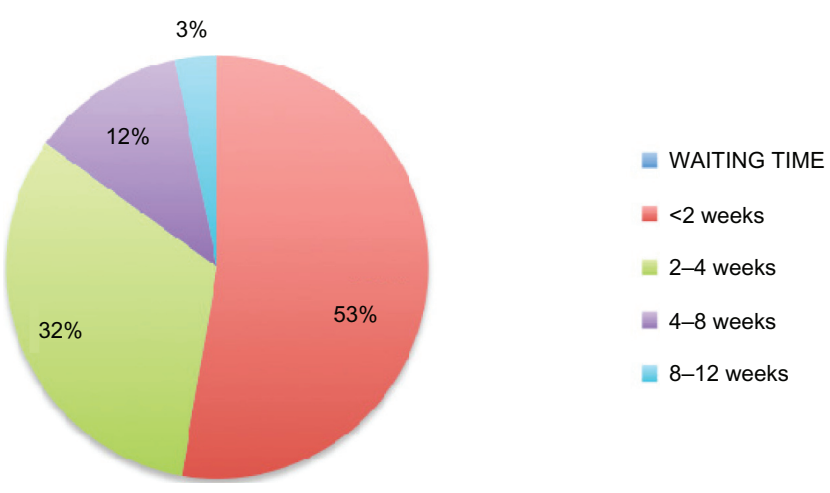

Figure 6 Majority of the patients referred because of a history of postmenopausal bleeding (PMB) were seen within 4 weeks. 


\section{Referral for GA}

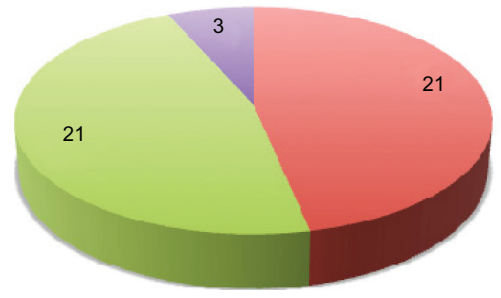

Figure 7 Indication for referral for hysteroscopy under general anesthesia (GA)

This project resulted in the debate on the feasibility of providing ultrasound and subsequent hysteroscopy in PMB patients within 2 weeks, if required. We believed that we would need service expansion to achieve this.

There were no therapeutic procedures carried out in the period audited, and we are presently looking at the expansion required to ensure that therapeutic procedures are incorporated into our outpatient hysteroscopy service.

\section{Conclusion}

Calderdale and Huddersfield National Health Service Trust has an effective diagnostic outpatient hysteroscopy service; however, there is a need to expand the service to reduce waiting times and incorporate therapeutic procedures into the service such as Versapoint polypectomy and endometrial ablation, which would in turn decrease the number of patients referred for hysteroscopy under general anesthesia.

\section{Disclosure}

The authors report no conflicts of interest in this work.

\section{References}

1. Harvard Health Publications. Hysteroscopy. 2007. Available from http://www.health.harvard.edu/fhg/diagnostics/hysteroscopy.shtml. Accessed Mar 15, 2010.

2. Clark TJ, Voit D, Song F, Hyde C, Gupta JK, Khan KS. Accuracy of hysteroscopy in the diagnosis of endometrial cancer and disease: a systematic review. JAMA. 2002;288:1610-1621.

3. Kremer C, Duffy S, Moroney M. Patient satisfaction with outpatient hysteroscopy vs day case hysteroscopy: a randomized controlled trial BMJ. 2000;320:279-282.
Clinical Audit

\section{Publish your work in this journal}

Clinical Audit is an international, peer-reviewed, open access journal focusing on the processes and outcomes of clinical audit in any area of healthcare. All aspects of patient care are addressed within the journal and practitioners from all disciplines are invited to submit their work. Areas covered include: Publication of audits; How an audit has changed practice;

\section{Dovepress}

Practical tips on how to do audits and to avoid pitfalls; How audits have changed patient care; Calls and justifications for new audits. The manuscript management system is completely online and includes a very quick and fair peer-review system, which is all easy to use. Visit http://www.dovepress. com/testimonials.php to read real quotes from published authors. 